\title{
Varietal specificity of polyphenols, free phenolics and antioxidant potential in hops
}

\author{
Alexandr Mikyška*, Marie Jurková \\ Research Institute of Brewing and Malting, PIc., Lípová 511/15, \\ 120 00, Praha 2, Czech Republic.
}

*correspondence e-mail: mikyska@berresearch.cz

\begin{abstract}
Many studies have confirmed hops (Humulus lupulus L.) as the source of a number of physiologically active polyphenols, important for both brewing and potentially pharmaceutical purposes. The three-year screening of polyphenols and 23 free phenolics profile (HPLC/coulometric detection) showed a significant association of polyphenols and free phenolics with DPPH antioxidant potential and the genetically determined specificity of free phenolics composition in hops. Varieties of American origin have a different profile compared to European varieties. For the first time, the free phenolics hydroxycoumarins were detected in hops. The DPPH strongly correlated with total polyphenols and flavanoids ( $n=95, r=0.92,0.93$ respectively) and correlated negatively with alpha acids $(n=95, r=-0.73$ ). The polyphenols and the DPPH decrease with increasing alpha acids both among varieties and within one variety. These findings can serve as a useful tool for hop selection in brewing or pharmaceutical production.
\end{abstract}

Keywords: Hops (Humulus lupulus L.); Polyphenols; Free phenolic substances; HPLC/Coulometric detection; DPPH antioxidant potential.

\section{Introduction}

It is generally accepted that hop (Humulus lupulus L.) cones are the source of a number of substances including polyphenols, important in terms of both brewing and health benefits. The influence of polyphenol substances on the quality of beer and its colloidal and sensory stability has been investigated for many decades, with often controversial results. Polyphenols are a highly diversified group of substances whose individual components are characterized by different properties in terms of chemical structure, antioxidant features, haze properties and hence an influence on beer stability. Hops is a specific raw material that has been investigated for the last few decades from the point of view of pharmaceutical use, as evidenced by the extensive review recently published by Karabín et al. (2016).

Secondary metabolites formed in the cones of hops during the flowering and ripening, e.g., bitter acids, es- sential oils and polyphenols, are sensory active and have antioxidant and antimicrobial properties. Hop polyphenolics comprise $3 \%$ to $6 \%$ of the dry weight of hop cones (Moir, 2000). The majority of polyphenols are located in the string and bract („leaf associated polyphenols“), prenylflavonoids are secreted from lupulin glands together with bitter acids and essential oils (Almaguer et al., 2014). Hop polyphenols are usually split into groups of flavonols, flavan-3-ols (catechins), phenolic carboxylic acids (groups of benzoic acid and cinnamic acid derivatives) and other phenolic compounds (prenylflavonoids, stilbenoids) (Biendl, 2009).

The analytical methods used for the determination of polyphenols are classed according to the purpose of their use. Group methods are based on the specific reactivity of a particular group of polyphenols and are included in the brewing analytics. They include in particular the 
determination of total polyphenols, flavanoids and anthocyanogens. Procedures based on a high-performance liquid chromatography with a mass spectrometer detection (Olšovská et al., 2013; Kavalier et al., 2011; Inui et al., 2017) or HPLC with a coulometric detection (Floridi et al., 2003; Jandera et al., 2005; Jurková et al., 2010) are applied for a detailed description of the profile of a particular group of polyphenol substances.

Hop polyphenols can act as antioxidants with beneficial effects on civilization diseases, tumors, atherosclerosis, diabetes, Alzheimer's disease and Parkinson's disease that threaten a substantial part of the human population. Antioxidant effects of polyphenols are characterized by their ability to scavenge reactive oxygen (ROS) or nitrogen species in the radical reaction chains of living cells (Ross and Kasum, 2002; Nemzer et al., 2011) and by their ability to suppress some specific enzymes involved in the generation of reactive oxygen species (Pieta, 2000; Stoclet et al., 2004), and they have a chelating effect on trace metal ions (copper and iron), thereby playing crucial roles in suppressing atherosclerosis (Quinones et al., 2013). Some polyphenols are particularly antimicrobially active and exert an inhibitory effect on a wide range of pathogenic bacteria (Sendamangalam et al., 2011; Cermak et al., 2015; Cermak et al., 2017; Daglia, 2012).

These properties of polyphenols are also manifested in the brewing process; the antioxidant and metal chelating activity helps to protect sensitive sensory active substances and improve the sensory stability of beer by suppressing the formation of stale flavor aldehydes (Mikyška et al., 2011; Boivin, 2008).

Previous studies have suggested some links between the content and composition of polyphenols, antioxidant activity and the origin of hops. The level of polyphenols can depend on soil climatic conditions, weather conditions during vegetation and ripening, hop plant age and harvest time. Polyphenols in the cone mass are formed in the earlier stages of the vegetation of the hop plant, while the metabolites of the lupulin glands are mainly formed during maturation (Kavalier et al., 2011). The content of polyphenols depends on the hop variety; aroma cultivars contain a higher number of polyphenols than bitter hops, because an increase in $\alpha$-acids can only be obtained at the expense of the polyphenol content (Kammhuber, 2005), and polyphenols extracted from hops using hot water are in a good relation with an antioxidant activity (Krofta et al., 2008).

These findings were obtained under a variety of conditions. The aim of our three-year study was to specify the relationship between the origin of hop polyphenols, the free phenolic compound profile and antioxidant activity.

\section{Material and Methods}

\subsection{Hop samples}

Samples of freshly harvested dried hops of the most widespread Czech cultivars Saaz, Sladek, Premiant and Agnus were obtained from the Chmelařství Cooperative Žatec. Samples originating from all three growing areas, Žatec, Úštěk and Tršice were selected from a wider collection to cover the growing regions. In three consecutive harvests, 95 hop samples were analyzed for total polyphenols, anthocyanogens and flavanoids and antioxidant potential. In the last year of the study, part of the samples from each variety was analyzed by the HPLC/CoulArray method to assay the profile of free phenolic substances, i.e. phenolic acids and flavonoids. In this year, the polyphenols and the profile of free phenolic compounds of the nine cultivars, Saaz, Saaz Late, Bohemie, Sladek, Harmonie, Rubin, Premiant, Agnus and Vital were also evaluated. The hops originated from the experimental hop plant of the Hop Research Institute in Žatec.

\subsection{Analyses}

Finely ground hops were extracted with boiling water under reflux ( $4.0 \mathrm{~g}$ dry matter of hops per 1 liter). After cooling, the solid was separated by centrifugation for $15 \mathrm{~min}$ utes at 6,000 RPM. The procedure is virtually identical with the extraction according to the European Brewery Convention (EBC) (Method 7.14; Analytica-EBC, 2010).

Total polyphenols (Method 7.14; Analytica-EBC, 2010): The determination is based on the reaction of polyphenols with ferric ions (ferric ammonium citrate) in an alkaline medium to produce a red color complex (photometry at $600 \mathrm{~nm}$ ).

Anthocyanogens (Method 2.16.2; MEBAK, 2011): Anthocyanogens (leucocyanidins, the standard is delphinidin chloride) react under acidic conditions to form red oxonium salts (photometry at $550 \mathrm{~nm}$ ).

Flavanoids (Method 9.12; Analytica-EBC, 2010): Flavanols (catechins and proanthocyanidins, the standard is catechin) react in an acidic environment with chromogen (p-dimethyl cinnamaldehyde) to give a green coloration (photometry at $640 \mathrm{~nm}$ ).

Determination of free phenolic compounds: Free phenolics comprising 23 compounds were determined using coulometric detection HPLC according to the procedure previously developed by Jurková et al. (2010). The quantified compounds included flavonoids: flavanols (catechin, epicatechin), flavonols (myricetin, quercetin, rutin), flavanone (naringin) and flavon (apigenin); free phenolic acids: hydroxycinnamic acids (ferulic, synaptic, p-coumaric, chlorogenic and caffeic acid), hydroxybenzoic acids (p-hydroxybenzoic, gallic, protocatechuic, genti- 
sic, vanillic and syringic); 4-hydroxyphenylacetic acid; hydroxycoumarins (4-hydroxycoumarin, umbelliferon, esculin and scopoletin). The results are given in $\mu \mathrm{g} / \mathrm{g}$ of hops.

Determination of antioxidant activity: The antioxidant (antiradical) activity was determined using the DPPH free radical according to a procedure developed previously by Krofta et al. (2008). The method particularly measures slowly reducing substances, especially polyphenols. ARP (antioxidant potential), i.e. an integrated decrease of DPPH value within 0-10 minutes of reaction, was determined.

\section{Results and Discussion}

A set of harvest samples of four significant domestic hop varieties, Saaz, Sladek, Premiant and Agnus was analyzed in three consecutive harvests for the content of polyphenols by group methods codified in the brewing method collections. The highest number of total polyphenols, as well as anthocyanogens and flavanoids was found in Saaz hops whereas the other three evaluated varieties did not differ significantly (Figure 1, Table 1). An important source of variation in the content of polyphenols within a variety was the growing site, understood as a set of soil climatic conditions, the course of the weather in a given year and the age of the hop plant. All these factors can influence the chemical composition of the hop cone (Jelínek et al., 2012). The relative standard deviation of the content of polyphenols

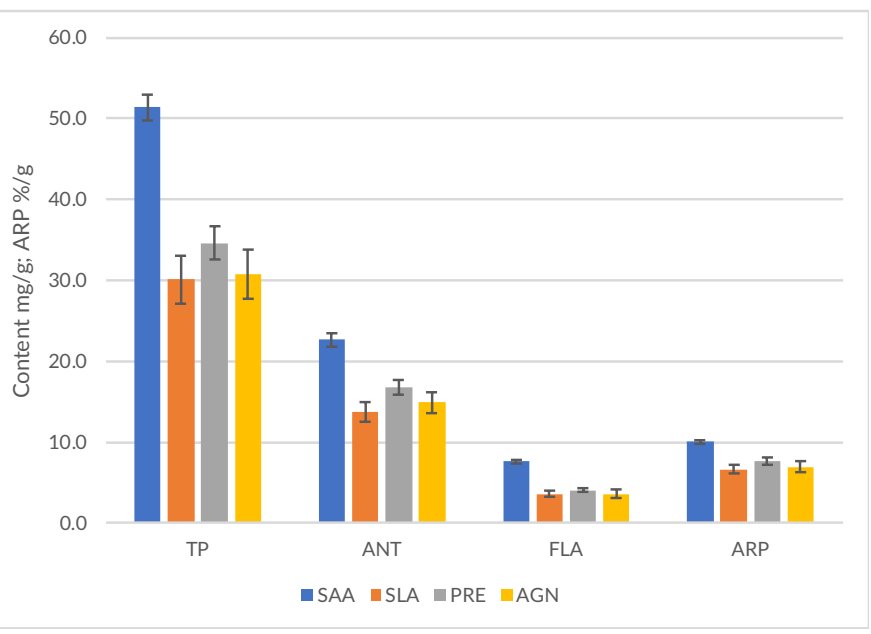

Figure 1 Comparison of total polyphenols, anthocyanogens, flavanoids an antioxidant potential in hops

SAA - Saaz; SLA - Sladek; PRE - Premiant; AGN - Agnus

TP - Total polyphenols; ANT - Anthocyanogens; FLA - Flavanoids; $A R P$ - Antioxidant potential

within the varieties varied in the range of about $6 \%$ to $20 \%$. The variability of polyphenols is thus comparable to that of alpha acids (Mikyška and Jurková, 2019). The least significant factor in the monitored years was the harvest year. A significantly higher value of total polyphenols and antioxidant activity of the Sladek and Premiant varieties was determined only in harvest $C$ versus harvest $A$.

The antioxidant potential (ARP), measured by the DPPH free radical, strongly correlated with polyphenol substances, and was also significantly higher in Saaz hops. The value of the antioxidant potential strongly

Table 1 The content of polyphenols, alpha acids and antioxidant potential in hops

\begin{tabular}{|c|c|c|c|c|c|c|c|c|c|c|c|}
\hline \multirow[b]{2}{*}{ Variety } & \multirow[b]{2}{*}{ Year } & \multicolumn{2}{|c|}{$\begin{array}{l}\text { Total Polyphenols } \\
\text { (mg/g) }\end{array}$} & \multicolumn{2}{|c|}{$\begin{array}{c}\text { Anthocyanogens } \\
\text { (mg/g) }\end{array}$} & \multicolumn{2}{|c|}{$\begin{array}{l}\text { Flavanoids } \\
\text { (mg/g) }\end{array}$} & \multicolumn{2}{|c|}{$\begin{array}{l}\text { ARP } \\
(\% / g)\end{array}$} & \multicolumn{2}{|c|}{$\begin{array}{l}\text { Alpha acids } \\
\text { (g/100g) }\end{array}$} \\
\hline & & $\mathrm{R}$ & SD & $\mathrm{R}$ & SD & $\mathrm{R}$ & SD & $\mathrm{R}$ & SD & $\mathrm{R}$ & SD \\
\hline \multirow{3}{*}{ Saaz } & A & 50.0 & 6.0 & 23.1 & 2.7 & 7.70 & 0.65 & 9.90 & 0.67 & 3.60 & 0.67 \\
\hline & B & 51.2 & 3.8 & 23.9 & 2.8 & 7.50 & 0.80 & 9.80 & 0.59 & 3.60 & 0.56 \\
\hline & C & 52.4 & 6.5 & 21.4 & 2.3 & 7.56 & 0.93 & 10.31 & 0.86 & 2.84 & 0.79 \\
\hline \multirow{3}{*}{ Sladek } & A & 26.5 & 3.6 & 12.5 & 2.2 & 3.30 & 0.57 & 5.80 & 0.94 & 5.90 & 0.84 \\
\hline & B & 30.6 & 7.3 & 13.5 & 3.1 & 3.45 & 0.85 & 6.38 & 1.17 & 7.74 & 1.32 \\
\hline & C & 31.0 & 4.2 & 14.3 & 1.5 & 3.77 & 0.63 & 7.18 & 0.77 & 8.62 & 1.71 \\
\hline \multirow{3}{*}{ Premiant } & A & 32.9 & 1.9 & 16.9 & 1.1 & 3.70 & 0.21 & 6.50 & 0.30 & 11.00 & 2.22 \\
\hline & B & 36.6 & 5.8 & 17.4 & 2.4 & 3.99 & 0.71 & 7.88 & 1.09 & 9.57 & 1.22 \\
\hline & $C$ & 33.5 & 1.7 & 16.2 & 1.2 & 4.26 & 0.39 & 7.96 & 0.31 & 9.00 & 1.28 \\
\hline \multirow{3}{*}{ Agnus } & A & 29.1 & 1.6 & 14.3 & 0.6 & 3.30 & 0.13 & 6.30 & 0.26 & 13.60 & 0.50 \\
\hline & B & 30.2 & 2.0 & 14.8 & 1.0 & 3.52 & 0.32 & 6.86 & 0.37 & 11.98 & 1.58 \\
\hline & C & 33.6 & 5.4 & 15.1 & 2.6 & 4.08 & 0.79 & 7.49 & 1.16 & 9.88 & 1.01 \\
\hline
\end{tabular}

R - Average; SD - Standard deviation; ARP - Antioxidant potential 
Table 2 Correlation of polyphenol substances in hops with antioxidant potential and alpha acids

\begin{tabular}{|c|c|c|c|c|}
\hline & TP & ANT & FLA \\
\hline \multicolumn{5}{|c|}{ All varieties } \\
\hline ARP & $0.92^{* *}$ & $0.87^{* *}$ & $0.93^{* *}$ & \\
\hline \multicolumn{5}{|c|}{-} \\
\hline ALPHA & $-0.77^{* *}$ & $-0.66^{* *}$ & $-0.83^{* *}$ & $-0.73^{* *}$ \\
\hline \multicolumn{5}{|c|}{ Saaz } \\
\hline ARP & $0.75^{* *}$ & $0.38^{* *}$ & $0.66^{* *}$ & \\
\hline \multicolumn{7}{|c|}{-} & $-0.27^{*}$ & $-0.42^{* *}$ \\
\hline ALPHA & $-0.35^{* *}$ & 0.07 &
\end{tabular}

${ }^{*} P<0.05 ;{ }^{* *} P<0.01$

ALPHA - Alpha acids; TP - Total polyphenols ; ANT - Anthocyanogens; FLA - Flavanoids; ARP - Antioxidant potential

(at the confidence level $\mathrm{P}=0.01$ ) correlated with the polyphenols both in the whole set of hop varieties and in a particular variety (Table 2 ). ARP depended inversely on alpha acids, both in the case of the whole set $(r=-0.73$, $\mathrm{P}=0.01$ ), obviously due to the higher content of polyphenols and a low content of alpha acids in Saaz hops compared to the other three varieties, as well as within the set of Saaz hops $(\mathrm{r}=-0.42, \mathrm{P}=0.01)$. This is probably caused by the different dynamics of formation of different groups of secondary metabolites of hops during vegetation. Polyphenol substances in hop cones (bracts and strings) are formed especially when the cone volume increases, an increase in alpha acid amount in lupulin glands occurs during maturation (Kavalier et al., 2011).

Compounds collectively measured as „total polyphenols ", both phenolic acids and flavonoids, represent the widest spectrum of substances, all of which are capable of reducing ferric ions to ferrous. Only flavanols (catechins and proanthocyanidins) are determined as "flavanoids", whereas, e.g., flavonols and their glycosides are not detected. „Anthocyanogens“ (leucoanthocyanidins, colorless catechins) are a group of substances capable of forming red-colored anthocyanidins in an acidic environment.

In order to obtain a more detailed view of hop monomeric polyphenols, part of hop samples from $C$ harvest was analyzed on the profile of free phenolic substances using HPLC/CoulArray.

The total content of free phenolic compounds, as well as groups of flavanols (catechins), benzoic acid derivatives and cinnamic acid, was the highest in Saaz hops. Rutin (quercetin-0-rutinoside) was a major substance in the flavonol group, its amount being considerably higher in Saaz and Agnus varieties compared to Sladek and Premiant. The occurrence of hop hydroxycoumarins has been detected e.g. in wine (Ghiselli et al., 1998), malt
(Dvorakova et al., 2008), and beer (Jandera et al., 2005), but according to available information these substances have not yet been measured in hops. Their content was the lowest in Saaz hops (Table 3). It is obvious that the profile of free phenolic substances in the tested hop varieties differs not only in quantity but also in the ratio of the chemically related groups of polyphenols (Figure 2). For example, in Saaz hops, $48 \%$ of the free phenolic compounds were flavanols while the proportion of flavanols in Sladek and Premiant hops was 29 and $27 \%$ respectively.

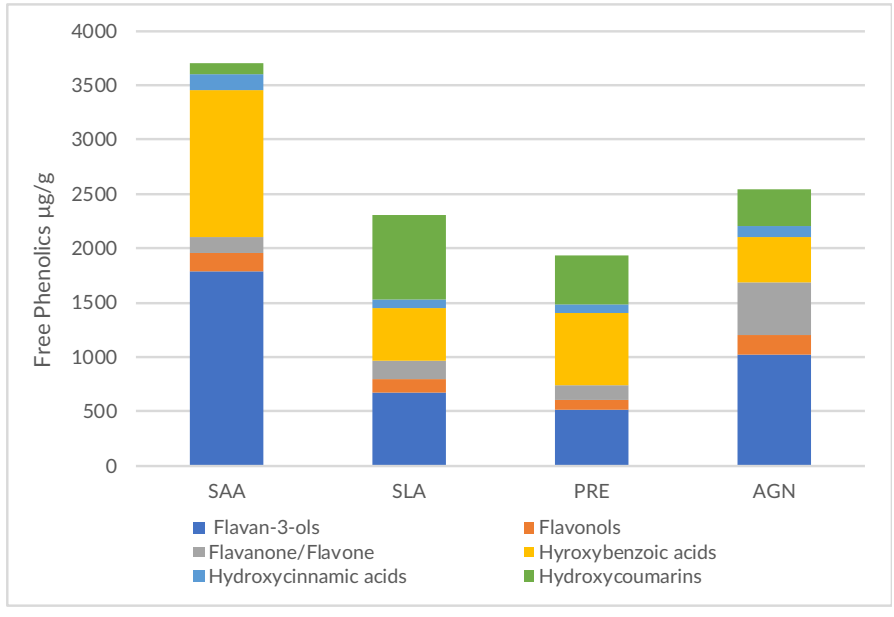

Figure 2 Profile of free phenolic substances in hops

SAA - Saaz; SLA - Sladek; PRE - Premiant; AGN - Agnus

The above-mentioned varietal dependence was further tested on a broader spectrum of samples of nine hop varieties grown at one location, the experimental hop gardens of the Hop Research Institute in Žatec. The results of analysis of total polyphenols, anthocyanogens and flavanoids confirmed the above-mentioned variation, the highest values being measured for Saaz hops and genetically closely related cultivar Saaz Late (Figure 3). Some genetically determined differences can be 
Table 3 The content of free phenolic compounds in hops ( $\mu \mathrm{g} / \mathrm{g})$

\begin{tabular}{|c|c|c|c|c|c|c|c|c|c|c|}
\hline & & & \multicolumn{2}{|c|}{ Saaz } & \multicolumn{2}{|c|}{ Sladek } & \multicolumn{2}{|c|}{ Premiant } & \multicolumn{2}{|c|}{ Agnus } \\
\hline & & & $\mathrm{R}$ & SD & $\mathrm{R}$ & SD & $\mathrm{R}$ & SD & $\mathrm{R}$ & SD \\
\hline \multirow{7}{*}{$\begin{array}{l}\frac{n}{0} \\
\frac{0}{0} \\
\frac{0}{\pi} \\
\frac{\pi}{4}\end{array}$} & \multirow[t]{2}{*}{ Flavan-3-ols } & Catechin & 1345 & 275 & 528 & 180 & 426 & 87 & 594 & 151 \\
\hline & & Epicatechin & 446 & 114 & 146 & 53 & 90 & 48 & 428 & 41 \\
\hline & \multirow{3}{*}{ Flavonols } & Myricetin & 1.9 & 1.1 & 3.2 & 0.7 & 0.8 & 0.6 & 1.6 & 0.9 \\
\hline & & Quercetin & 9.0 & 3.0 & 30.5 & 58.3 & 12.4 & 1.1 & 1.8 & 0.3 \\
\hline & & Rutin & 154 & 61 & 90 & 34 & 80 & 11 & 175 & 18 \\
\hline & Flavanones & Naringin & 58.4 & 19.5 & 152.5 & 129.0 & 81.8 & 9.3 & 481.3 & 28.8 \\
\hline & Flavones & Apigenin & 86.7 & 96.4 & 17.7 & 33.7 & 43.8 & 26.3 & 0.0 & 0.0 \\
\hline \multirow{15}{*}{ 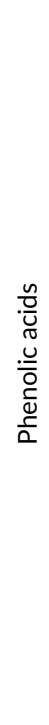 } & \multirow{5}{*}{$\begin{array}{l}\text { Hydroxycinnamic } \\
\text { acids }\end{array}$} & Ferulic acid & 13.4 & 4.1 & 16.1 & 2.5 & 9.3 & 1.8 & 15.8 & 1.5 \\
\hline & & Sinapic acid & 3.6 & 3.1 & 4.6 & 1.5 & 2.7 & 0.3 & 6.3 & 4.3 \\
\hline & & Coumaric acid & 6.3 & 1.2 & 17.1 & 3.8 & 8.1 & 1.5 & 19.8 & 2.8 \\
\hline & & Chlorogenic acid & 112.3 & 37.7 & 26.5 & 17.8 & 41.7 & 4.8 & 35.6 & 1.1 \\
\hline & & Caffeic acid & 16.4 & 7.8 & 15.2 & 3.0 & 15.7 & 3.4 & 23.8 & 2.8 \\
\hline & \multirow{6}{*}{$\begin{array}{l}\text { Hydroxybenzoic } \\
\text { acids }\end{array}$} & p-Hydroxybenzoic acid & 1173 & 159 & 346 & 67 & 487 & 115 & 274 & 29 \\
\hline & & Gallic acid & 4.4 & 1.5 & 4.1 & 1.7 & 13.7 & 7.6 & 1.3 & 0.3 \\
\hline & & Protocatechuic acid & 17.9 & 1.5 & 10.0 & 1.7 & 44.3 & 12.7 & 10.8 & 0.5 \\
\hline & & Gentisic acid & 90.9 & 75.1 & 67.0 & 6.3 & 96.5 & 34.7 & 58.8 & 4.3 \\
\hline & & Vanillic acid & 24.6 & 12.3 & 12.6 & 7.8 & 11.0 & 12.8 & 17.3 & 1.3 \\
\hline & & Syringic acid & 38.0 & 32.5 & 41.4 & 18.0 & 17.0 & 2.8 & 49.8 & 44.8 \\
\hline & \multirow{4}{*}{ Hydroxycoumarins } & 4-Hydroxycoumarin & 56.5 & 33.4 & 549.2 & 97.9 & 341.3 & 39.4 & 235.5 & 82.5 \\
\hline & & Umbelliferon & 5.5 & 3.8 & 21.7 & 9.5 & 13.4 & 10.6 & 6.1 & 1.4 \\
\hline & & Esculin & 1.3 & 0.5 & 3.0 & 1.6 & 2.6 & 3.9 & 3.4 & 2.1 \\
\hline & & Scopoletin & 36.0 & 15.6 & 203.3 & 117.1 & 22.0 & 11.5 & 101.3 & 66.8 \\
\hline
\end{tabular}

$R$ - Average; SD - Standard deviation

traced in the profile of free phenolic substances (Figure 4), which have already been indicated in the results of the three-year screening of the basic set of varieties. The two very close varieties, Saaz and Saaz Late (a Saaz-based variety with a longer growing season cultivated to counteract climate change) showed a similarity of both the quantitative and qualitative profile of phenolic substances.

The genetic relatedness of varieties was evaluated by a dendrogram of 135 traditional and new world hop cultivars recently developed by Patzak and Henychová (2018).The varieties included in the hop varieties of European origin of the Saaz group (ES) and the Fuggle group (EF) had a catechin content in excess of three to four times the epicatechin content, whereas hops from the American hops group (AM), Agnus and Vital had a ratio of these epimers close to one. The varieties included in the hop varieties of European origin of the Fuggle group (Sladek, Harmonie and Premiant/Premiant was previously grouped

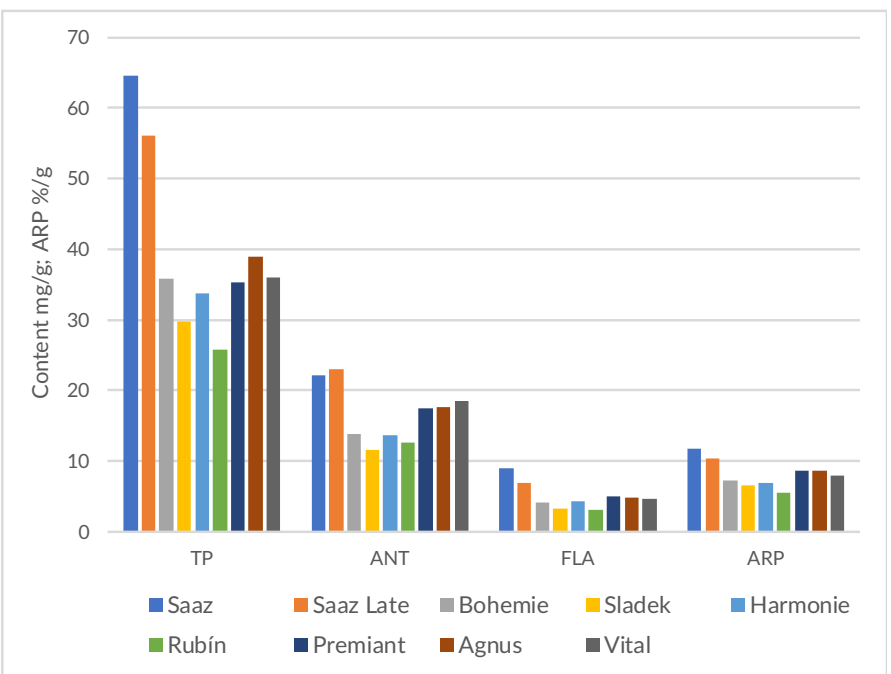

Figure 3 Comparison of total polyphenols, anthocyanogens, flavanoids an antioxidant potential in nine hop varieties

TP - Total polyphenols; ANT - Anthocyanogens; FLA - Flavanoids; $A R P$ - Antioxidant potential 
in the Fuggle group, similar to Northern Brewer, currently belonging to the Saaz group) and the variety of mixed origin (MIX) Rubin contained significantly higher amounts of hydroxycoumarins compared to the varieties of American origin and European origin of the Saaz group. Biosynthesis of coumarins takes place by ortho-hydroxylation of cinnamic acid to form coumaric acid, and its subsequent lactonization (Velíšek, 2002). It is possible that in a particular group of hops this metabolic pathway is suppressed.

The content of chemically related phenolic compounds was correlated with the antioxidant potential of hops (Table 4). A positive relationship, significant at $\mathrm{P}=0.01$, was found for flavan-3-ols ( $r=0.921)$, cinnamic acid derivatives $(r=0.770)$ and chlorogenic acid derivatives $(r=0.894)$. However, due to the correlation between flavan-3-ols and phenolic acid groups, the contribution of the two types of compounds to antioxidant capacity cannot be assessed. The antioxidant potential of flavonoids is determined by their chemical structure, the number and position of $\mathrm{OH}$ groups on the aromatic nucleus, the $\mathrm{OH}$ groups at C4 'and C3' being the major determinants. Catechin and epicatechin therefore also belong to these substances (Nowak et al., 2014). Conversely, a negative relationship at the level of $\mathrm{P}=0.05$ was found for antioxidant potential and hydroxycoumarins $(r=-0.665)$. Varieties with a higher content of hydroxycoumarins had weaker antioxidant properties.

When using hops for pharmaceutical purposes or for producing various dietary supplements, the amount of substances that are the target of raw hops processing is important. The usage in beer brewing is specific in that the hop dose is governed by the desired bitterness of beer, and therefore it is determined by the content of alpha acids in the hop product. The ratio of the polyphenols and alpha acids is crucial for enhancing the content of polyphenol antioxidants in beer. It is obvious that the effect of hopping by aroma varieties with low alpha acids is significantly higher compared to bitter hop varieties (Figure 5). The influence of the year of harvest and the growing location on the ratio of polyphenols and alpha acids is considerably less significant (Figure 6). However, these factors may be influential in the event of extreme harvests.

Our study was focused both on the antioxidant profile of hop varieties and on revealing the varietal specificity of phenolic compounds profile in hops. A strong

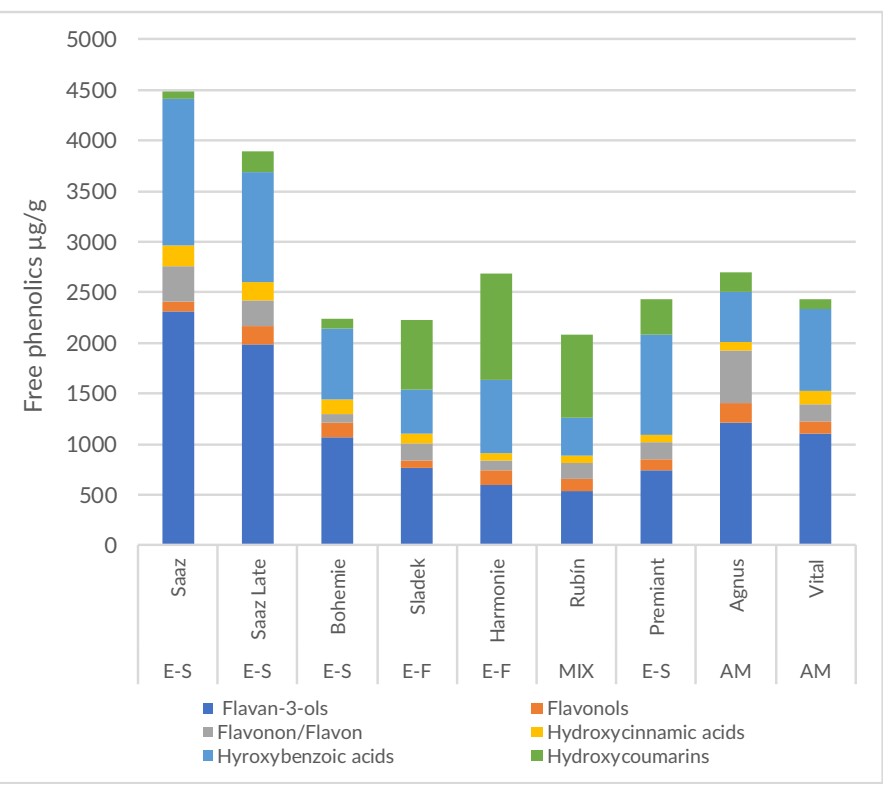

Figure 4 Profile of free phenolic substances in nine hop varieties

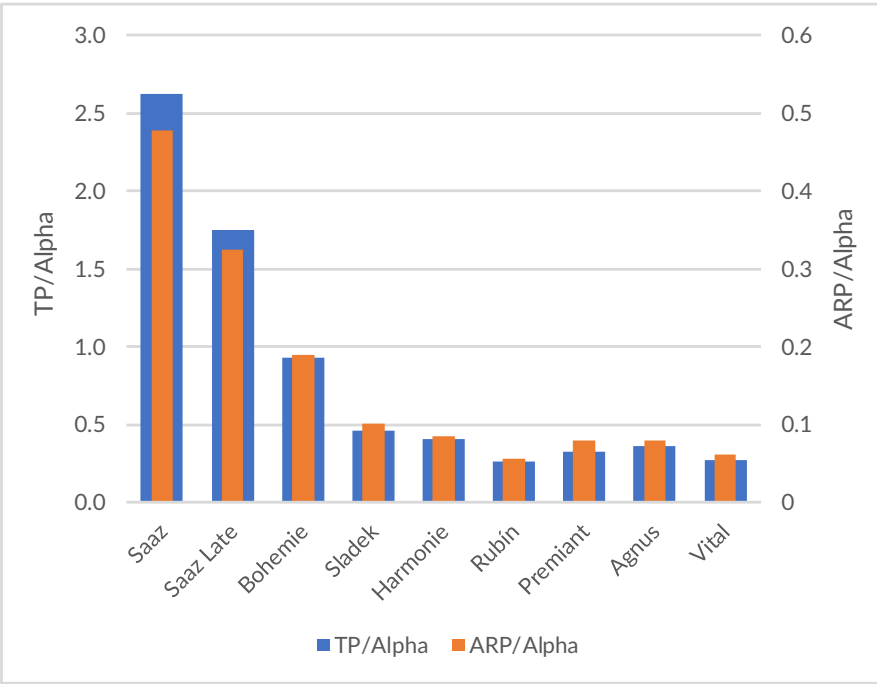

Figure 5 Comparison of the ratio of total polyphenols and antioxidant potential to alpha acids

TP/Alpha - Total polyphenols to alpha acids ratio

ARP/Alpha - Antioxidant potential to alpha acids ratio

relationship to the antioxidant potential was confirmed for polyphenol content, catechins (flavanoids) and phenolic acids (total polyphenols). The study of free phenolic compounds has shown that the profile and content of polyphenols in hops appear to be significantly genetically determined, differing in American and European varieties. However, the contribution of different groups of free phenolics to antioxidant activity is still unclear because of the cross-correlations of groups of flavanoids and phenolic acids. Hydroxycoumarins were detected in hops for the first time, and their content was inversely related to the antioxidant potential of hops. 
Table 4 Correlation of free phenolic substances in hops with antioxidant potential

\begin{tabular}{|l|c|c|c|c|c|}
\hline & $\begin{array}{c}\text { Total free } \\
\text { phenols }\end{array}$ & Flavan-3-ols & Flavonols & $\begin{array}{c}\text { Hydroxycin- } \\
\text { namic acids }\end{array}$ & $\begin{array}{c}\text { Hyroxybenzoic } \\
\text { acids }\end{array}$ \\
\hline Flavan-3-ols & $0.82^{* *}$ & & & & \\
\hline Flavonols & -0.16 & 0.07 & & & \\
\hline Hydroxycinnamic acids & $0.71^{* *}$ & $0.89^{* *}$ & -0.16 & & \\
\hline Hyroxybenzoic acids & $0.88^{* *}$ & $0.65^{* *}$ & -0.35 & $0.67^{* *}$ & \\
\hline Hydroxycoumarins & -0.31 & $-0.75^{* *}$ & -0.25 & $-0.72^{* *}$ & -0.28 \\
\hline ARP & $0.92^{* *}$ & $0.93^{* *}$ & 0.04 & $0.78^{* *}$ & $0.81^{* *}$ \\
\hline
\end{tabular}

** $P<0.01 ; A R P-$ Antioxidant potential

The findings achieved in our study may be a useful tool for selecting hops in a brewery or to produce extracts for pharmaceutical purposes, but further research is needed to formulate varietal profiles.

\section{Acknowledgement}

This work was supported by the Ministry of Agriculture of the Czech Republic within the institutional support MZE-R01918 and by the Technology Agency of the Czech Republic within the Competence Center, project TE02000177.

\section{References}

Almaguer, C.; Schonberger, C.; Gastl, M.; Arendt, E.K.; Becker, T. (2014). Humulus lupulus - a story that begs to be told. A review. Journal of the Institute of Brewing 120(4), 289314. https://doi.org/10.1002/jib.160

Analytica-EBC, Fachverlag Hans Carl, Nuremberg, 2010.

Biendl, M. (2009). Hops and health, Technical Quarterly - Master Brewers Association of the Americas 46, 1-7. DOI:10.1094/TQ-46-2-0416-01

Boivin, P. (2008). Relationship between polyphenols and beer flavour stability. Cerevisia 33(4), 188-195.

Cermak, P.; Paleckova, V.; Houska, M.; Strohalm, J.; Novotna, P.; Mikyska, A.; Jurkova, M.; Sikorova, M. (2015). Inhibitory effects of fresh hops on Helicobacter pylori strains. Czech Journal of Food Sciences 33(4), 302-307. https://doi.org/10.17221/261/2014-CJFS

Cermak, P.; Olsovska, J. ; Mikyska, A.; Dusek, M. ; Kadleckova, Z.; Vanicek, J.; Nyc, O.; Sigler, K. ; Bostikova, V. ; Bostik, P. (2017). Strong antimicrobial activity of xanthohumol and other derivatives from hops (Humulus lupulus L.) on gut anaerobic bacteria. APMIS 125(11), 1033-1038. https://doi.org/10.1111/apm.12747

Daglia, M. (2012). Polyphenols as antimicrobial agents. Current Opinion in Biotechnology 23(2), 174-181. https://doi.org/10.1016/j.copbio.2011.08.007

Dvorakova, M.; Douanier, M.; Jurkova, M.; Kellner, V.; Dostalek, P. (2008). Comparison of antioxidant activity of barley (Hordeum vulgare L.) and malt extracts with the content of free phenolic compounds measured by high performance liquid chromatography coupled with CoulArray detector. Journal of the Institute of Brewing 114(2), 150159. https://doi.org/10.1002/j.2050-0416.2008.tb00320.x

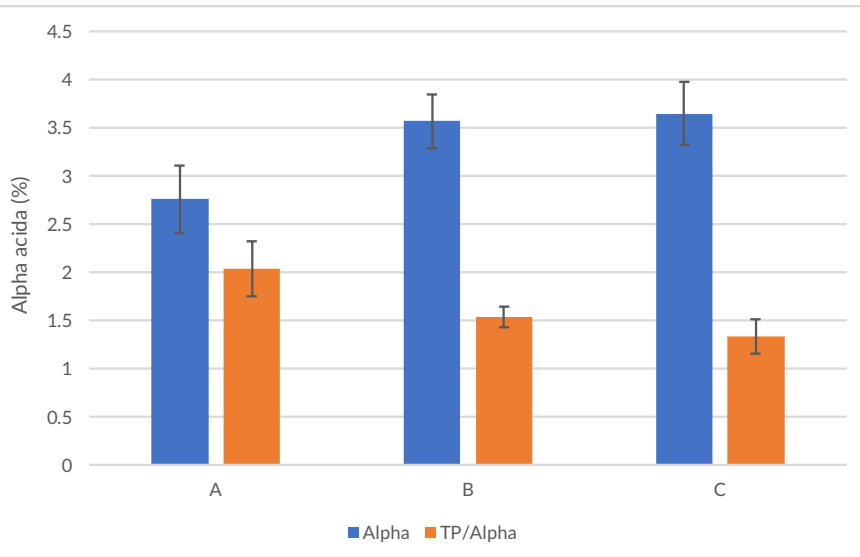

igure 6 The content of total polyphenols and total polyphenols ratio to the alpha-acids in different harvests

Alpha - Alpha-acid content

TP/Alpha - Total polyphenols to alpha acids ratio

A, $\mathrm{C}$ - Harvests under study

Floridi, S.; Montanari, L.; Marconi, O.; Fantozzi P. (2003). Determination of free phenolic acids in wort and beer by coulometric array detection. Journal of Agricultural and Food Chemistry 51(1-2), 1548-1554. https://doi.org/10.1021/jf0260040

Ghiselli, A.; Nardini, M.; Baldi, A.; Scaccini, C. (1998). Antioxidant activity of different phenolic fractions separated from an Italian red wine. Journal of Agricultural and Food Chemistry 46(2), 361-367. https:// doi.org/10.1021/jf970486b

Inui, T.; Okumura, K.; Matsui, H.; Hosoya, T.; Kumazawa, S. (2017). Effect of harvest time on some in vitro functional properties of hop polyphenols. Food Chemistry 225, 69-76. https://doi.org/10.1016/j.foodchem.2017.01.002

Jandera, P.; Škeř́ková, V.; Řehovcová, L.; Hájek, T.; Baldrinová, L.; Škopová, V.; Kellner, V.; Horna, A. (2005). RP-HPLC analysis of phenolic compounds and flavonoids in beverages and plant extracts using a CoulArray detector. Journal of Separation Science 28, 1005-1022. https://doi.org/10.1002/jssc.200500003

Jelínek, L.; Dolečková, M.; Karabín, M.; Hudcová, T.; Kotlíková, B.; Dostálek, P. (2012). Influence of growing area, plant age, and virus infection on the contents of hop secondary metabolites. Czech Journal of Food Sciences 30, 541-547. https://doi.org/10.17221/50/2012-CJFS

Jurková, M.; Kellner, V.; Čulík, J.; Horák, T.; Čejka, P.; Karásek, P. (2010). Analysis of polyphenols in brewing raw materials by PSE (Pressurized Solvent Extraction) - and by HPLC method with CoulArray detection. Kvasny prumysl 56 (1), 18-23. https://doi.org/10.18832/kp2010003 
Kammhuber, K. (2005). Differentiating between the world range of hop varieties according to bitter compounds and polyphenols, Hopfen-rundschau International 2005/2006, 42-46.

Karabín, M.; Hudcová, T.; Jelínek, L.; Dostálek, P. (2016). Biologically Active Compounds from Hops and Prospects for Their Use. Comprehensive Reviews in Food Science and Food Safety 15, 1-26. https://doi. org/10.1111/1541-4337.12201

Kavalier, AR.; Litt, A.; Ma, C., Pitra, NJ.; Coles, MC.; Kennelly, EJ.; Matthews, PD. (2011). Phytochemical and Morphological Characterization of Hop (Humulus lupulus L.) Cones over Five Developmental Stages Using High Performance Liquid Chromatography Coupled to Timeof-Flight Mass Spectrometry, Ultrahigh Performance Liquid Chromatography Photodiode Array Detection, and Light Microscopy Techniques. Journal of Agricultural and Food Chemistry 59, 4783-4793. https://doi.org/10.1021/jf1049084

Krofta, K.; Mikyška, A.; Hašková, D. (2008). Antioxidant characteristics of hops and hop products. Journal of the Institute of Brewing 114 (2), 160-166. https://doi.org/10.1002/j.2050-0416.2008.tb00321.x

MEBAK. Collection of Brewing Analysis Methods of the Mitteleuropäische Brautechnische Analysenkommission, Freising-Weihenstephan, 2011.

Mikyška, A.; Jurková, M. (2019). Analysis and prognosis of bitter acids content in Czech hop varieties - year 2018 and long-term comparisons and trends. Kvasny prumysl 65(1), 23-31. https://doi. org/10.18832/kp2019.65.23

Mikyška, A.; Krofta, K.; Hašková, D.; Čulík, J.; Čejka, P. (2011) The influence of hopping on formation of carbonyl compounds during storage of beer. Journal of the Institute of Brewing 117(1), 47-54. https://doi. org/10.1002/j.2050-0416.2011.tb00442.x

Moir, M. (2000). Hops - a millennium review. Journal of American Society of Brewing Chemists 58(4), 31-46. https://doi.org/10.1094/ASBCJ-58-0131

Nemzer, BV.; Rodriguez, LC.; Hammond, L.; Di Silvestro, R.; Hunter, JM.; Pietrzkowski, Z. (2011). Acute reduction of serum 8-iso-PGF2-alpha and advanced oxidation protein products in vivo by a polyphenol-rich beverage; a pilot clinical study with phytochemical and in vitro antioxidant characterization. Nutrition Journal 10(1), 1-11. https://doi.org/10.1186/1475-2891-10-67
Nowak, R.; Olech, M.; Nowacka, N. (2014). Plant polyphenols as chemopreventive agents. In: Watson, R.; Preedy, V.; Zibadi, S. editors. Polyphenols in human health and disease. Elsevier Inc., San Diego, 2014, pp 1289-1307. https://doi.org/10.1016/B978-0-12-3984562.00086-4

Olšovská, J.; Kameník, Z.; Čejka, P.; Jurková, M.; Mikyška, A. (2013). Ultra-high-performance liquid chromatography profiling method for chemical screening of proanthocyanidins in Czech hops. Talanta 116, 919-926. https://doi.org/10.1016/j.talanta.2013.07.067

Patzak, J.; Henychová, A. (2018). Evaluation of genetic variability within actual hop (Humulus lupulus L.) cultivars by an enlarged set of molecular markers. Czech Journal of Genetics and Plant Breeding 54, 86-91. https://doi.org/10.17221/175/2016-CJGPB

Pietta, PG. (2000). Flavonoids as antioxidants. Journal of Natural Products 63(7):1035-1042. https://doi.org/10.1021/np9904509

Quinones, M.; Miguel, M.; Aleixandre, A. (2013). Beneficial effects of polyphenols on cardiovascular disease. Pharmacological Research 68(1), 125-131. https://doi.org/10.1016/j.phrs.2012.10.018

Ross, JA.; Kasum, CM. (2002). Dietary flavonoids: Bioavailability, metabolic effects, and safety. Annual Review in Nutrition 22, 19-34. https:// doi.org/10.1146/annurev.nutr.22.111401.144957

Sendamangalam, V.; Choi, OK.; Kim, D.; Seo, Y. (2011). The effect of polyphenols against Streptococcus mutans. Biofouling 27(1), 13-19. https://doi.org/10.1080/08927014.2010.535897

Stoclet, JC.; Chataigneau, T.; Ndiaye, M.; Oak, MH.; El Bedoui, J.; Chataigneau, M.; Schini-Kerth, VB. (2004). Vascular protection by dietary polyphenols. European Journal of Pharmacology 500(1-3), 299313. https://doi.org/10.1016/j.ejphar.2004.07.034

Velíšek, J. (2002). Chemie potravin (Chemistry of food), 2nd edition, OSSIS, Praha. ISBN 80-86659-00-3 (in Czech). 